Articles

4-2010

\title{
Leaders as Linchpins for Framing Meaning
}

Pamela L. Eddy

College of William \& Mary, pamela.eddy@wm.edu

Follow this and additional works at: https://scholarworks.wm.edu/articles

Part of the Community College Leadership Commons, and the Educational Leadership Commons

\section{Recommended Citation}

Eddy, Pamela L., "Leaders as Linchpins for Framing Meaning" (2010). Articles. 62.

https://scholarworks.wm.edu/articles/62

This Article is brought to you for free and open access by W\&M ScholarWorks. It has been accepted for inclusion in Articles by an authorized administrator of W\&M ScholarWorks. For more information, please contact scholarworks@wm.edu. 


\title{
Leaders as Linchpins for Framing Meaning
}

\begin{abstract}
Community college leaders serve as linchpins for framing meaning on campus. The current pressures on institutions given declining financial resources, demands for accountability, changing faculty ranks, and societal need for new knowledge means that presidents must juggle multiple priorities, while presenting a cohesive message to campus constituents. The research question addressed how leaders frame meaning on their campuses to make sense of ongoing change. Nine community college campuses served as case sites, with 75 total interviews conducted. Findings reveal that leaders made use of emissaries to spread meaning and disseminated information via four general formats. The research concluded that leaders operate using Visionary Framing, Step-by-Step Framing, or Connective Framing. Understanding the impact of framing style regarding campus change can help move organizational change forward.
\end{abstract}

College leaders are judged by what they say and do on campus. Campus constituents come to their own conclusions about what is going on based on how presidents communicate their vision and plans. Leaders, then, have the ability to frame information, as well as how constituents make meaning of that information, on their campuses (Eddy, 2003; Fairhurst \& Sarr, 1996; Neumann, 1995). When leaders frame information for campus members, they offer their own interpretations above others, much as a picture frame focuses one's attention on a particular view or aspect of a picture or painting. College presidents communicate and frame information for campus constituents in a variety of ways. In choosing how to frame issues on campus, presidents must be mindful of how the message might be interpreted by various stakeholders. How information is relayed on campus is becoming increasingly important during this period of intensive change in higher education as rumors abound, leadership transitions occur, and strategic planning is implemented.

Community colleges provide a useful site for investigating the president's role in framing meaning on campus. Two-year colleges educate nearly half of all undergraduates in the United 
States (National Center for Education Statistics [NCES], 2007). Long touted as a route of access for students given their proximity in communities and low cost, community colleges are now in the spotlight as a lever for economic recovery, and associate's degrees are being advocated as the minimum educational requirement for employees. At the same time, these colleges are facing financial challenges as states cut back funding for these already underfunded institutions (NCES, 2007) and as leadership is anticipated to undergo mass turnover, with predictions of $84 \%$ of twoyear colleges presidents expected to retire in the next 10 years (Weisman \& Vaughan, 2007). Given this backdrop, the research question for this study was How do leaders frame meaning on their campuses to make sense of ongoing change?

\section{Background Literature and Project Summary}

College leaders must pay attention to the messages they send to campus members, students, and the community because their messages provide a sense of direction. Presidents do not communicate in a vacuum. Both leaders and followers play a role, with leaders providing one way of interpreting a piece of information, and followers then interpreting this reality either in the suggested manner (i.e., in the manner that leaders intend) or in their own (Fairhurst, 2001). Leaders and followers both make meaning of what they hear and see through interactions with each other on campus (Berger \& Luckmann, 1966). But when leaders chose to frame information in different ways, it results in different interpretations by followers (Kelman, 1961). Before leaders can frame information for others, however, they must first make sense of it for themselves. This research explores how leaders communicate and frame information on campus. In particular, this research reviews the role of sensemaking by drawing on case studies of presidential leadership at nice community colleges. The college presidents were interviewed, as 
well as key campus members from the leadership cabinet, faculty, and staff. The findings highlight the role of the messenger and ways in which leaders work to get their messages across.

Times of uncertainty and change provide ripe opportunities for leaders to help campus members make sense of new events, and to connect new information with past experiences (Senge, 1990; Weick, 1995). Yet as Weick (1995) points out, "sensemaking begins with the sensemaker" (p. 18). College presidents thus need to create a sense of their own understanding before they can help others make meaning of campus events and planning. In sensemaking, leaders draw on their own personal ways of interpreting and creating knowledge, as well as on past experiences and interactions with campus members. Weick's sensemaking model, which contains seven properties, is useful in understanding how one moves through the process of sensemaking. As leaders become adept at making sense of a new situation for themselves and then communicating that understanding to others, they begin to serve as "sense-givers" (Thayer, 1988, p. 250, italics in the original). "The actions and utterances of leaders frame and shape the context of action in such a way that the members of that context are able to use the meaning thus created as a point of reference for their own action and understanding of the situation" (Smirich \& Morgan, 1982, p. 261). Followers have an expectation that their leaders will provide guidance regarding campus change.

A variety of tools exist for framing information, including rituals or traditions, stories, jargons, and metaphors. In particular, creating an institutional saga (Clark, 1972) can help constituents reflect on the culture of the college and interpret new information in a way that is consistent with its mission and goals. How leaders communicate and frame information is linked to leadership approaches and communication styles (Fairhurst, 2001), and presidents' leadership preferences affect the ways in which they frame new information for campus constituents. 
When framing information to campus constituents, leaders must be aware of the existing campus culture, as well as the prevailing attitudes and experiences of the faculty, the staff, and students. By interacting with all campus members—including students—leaders can learn about the context in which they are working, which in turn should influence the way that they frame and communicate information to others. Symbols and stories can also help leaders frame and communicate a message (Bolman \& Deal, 2008; Frost \& Morgan, 1983). Indeed, leaders can use symbols to draw attention to specific versions of a campus story they are creating.

The data for this research are based on findings from site visits at community colleges across the country. The colleges included two in the northeast, one in the west, one in the southwest, and five campuses that are part of a large district in the south. Because shifts in leadership often provide opportunities to enact change initiatives on college campuses (Birnbaum, 1992), I based my examination of community college leaders at colleges that had recently hired a new president. All sites were undergoing some form of organizational changeeither dictated by responses to external stimuli or attributed to internal motivations on the part of the president or at the urging of the campus community. Purposeful selection of sites occurred to cover various regions of the country and to represent the contextual issues facing the broad range of community colleges. A hermeneutic approach (Van Manen, 1990) was used in these case studies and involved semi-structured interviews with nine college presidents, as well as campus faculty, staff, and senior administrators. Interview questions focused on uncovering how leaders defined their leadership and the way they led their campuses through change efforts.

Specifically, the interviews sought to determine how the college presidents communicated about change on campus and in turn, how campus members perceived and interpreted the presidents' 
framing of new initiatives. Of particular interest was the communication process regarding the intentions of the presidents' messages and how campus followers understood the messages.

The framework for analysis used Weick's (1995) sensemaking model, with a focus on how framing occurred. According to Merriam (1998), "By concentrating on a single phenomenon or entity (the case), the researcher aims to uncover the interaction of significant factors characteristic of the phenomenon" (p. 29). In this instance, the focus within each case site was to better understand presidents' use of framing. Data analysis involved looking for patterns in the participant interviews (Stake, 1995), which were audiotaped and transcribed. Relational patterns were most obvious when presenting the data in tabular form. The use of multiple case sites allowed for cross-case analysis, providing for a better understanding of the influence of local conditions on findings. Each president was assigned a code to designate the gender and race of the president (i.e., $\mathrm{M}=$ male; $\mathrm{F}=$ female; $\mathrm{B}=\mathrm{black}$; $\mathrm{W}=$ white). Though analysis by gender and race did not occur per se, this background provides the reader with a sense of context that allows for interpretations that may challenge perceived assumptions of communication style and approach based on gender and race. Additionally, the interviews were coded by institutional location ( $\mathrm{NE}=$ northeast; $\mathrm{W}=$ =west; $\mathrm{S}=$ =south; $\mathrm{SW}=$ southwest), and finally number of case sites in each geographic region. Table 1 provides a template for the coding framework used for the quotes. For example, FW-NE-2 denotes reference to a female, white president leading an institution in the Northeast. The number " 2 " indicates the number assigned to the case site, with these numbers ranging from 1 to 9 .

[[Insert Table 1 About Here]] 


\section{Findings}

Framing occurred in a variety of formats on each of the nine campuses studied. Common to all campuses was the use of emissaries to help get the message across. Leaders use messengers in a variety of ways to support their framing and to help tell the campus story. Second, getting the message out occurred via four venues: Talking the Frame, Walking the Frame, Writing the Frame, and Symbolizing the Frame. Leaders typically favored one form over another to deliver their messages, but a combination of all four varieties proved most effective.

\section{Role of the Messenger}

More recent conceptions of leadership envision leadership operating at many levels throughout the college (Peterson, 1997). As community colleges have become more complex, it has become impossible for a college president to be everywhere and do everything. Increased demands on presidents result in leaders relying on others in the college's leadership circle to play a role in framing and communicating information to the faculty, the staff, and students. Just because a leader relies on messengers to help spread her message does not mean that the way in which she chooses to frame the information is less important or impactful. Indeed, if a variety of messengers or emissaries are enlisted to spread a particular message in a consistent and oftrepeated manner, chances are greater that members of the community will receive the same message regarding interpretations of campus plans and be on the same page. College cultures are based on shared stories, rituals, and understandings; leaders who understand the culture of their institution can simultaneously reinforce it and use it to share information with constituents.

Lunenburg and Ornstein (2007) have identified five basic ways in which information is disseminated within an organization: through chains, Y-networks, circles, wheels, and stars. In chain networks, presidents pass information to their vice-presidents, who in turn tell the deans 
who ultimately inform the faculty. This type of communication is highly structured and is often found in the military and other hierarchical organizations. Y-networks are similar in that information is shared in one direction only, but there may be more than one source of information in Y-network communication.

Circle networks are also autocratic, as the leader controls the information that is passed around the circle. In this communication pattern, individuals interact with a limited number of people - those located on either side of them in the circle (in community colleges, this might mean that a president communicates mainly with his vice presidents or with the leaders of the academic senate). The director of outreach at the college in the west described the circular communication route at her college by noting that, "The president has kind of closed herself off, to be honest. Instead of having a large president's council like we had with about 15 people, all the deans, some of the directors and the V.P.s, she went to a strict 'I talk to three people' model, and I don't think it has benefited her in terms of communication." At this western college, the president (FW-W-3) is located at the top of her circular communication network and uses the messengers closest to her to pass along information. In turn, she receives information only from this same limited circle.

In wheel communication networks, the leader is positioned in the center of a wheel, and passes information to the campus community along the spokes (e.g., a president may use the vice president of academic affairs to communicate with her deans and faculty, or may rely on the vice president of student services to pass information to counselors and financial aid officers. A president at a campus in the south described the wheel communication model when he stated, " $A$ lot of communication goes down, not directly from me, it goes through other people. When we 
have our meetings these president council meetings every week I'm sure I'm told a lot of stuff from the meetings that gets transferred down" (MW-S-5).

What differentiates the wheel model from a chain or Y-network is that people located at the other end of a spoke are able to access the leader without having to go through another layer of the hierarchy. Additionally, those at the outer level of the wheel have access to one another. By incorporating additional avenues for communication at many levels, the wheel can be effective in reinforcing stories and perspectives that the leader wants to highlight. For instance, several different staff members at a campus in the northeast shared the same vision for their campus. The president said, "In a very flippant way our goal is to graduate students who not only have a very valuable degree, but walk across the stage with a degree in one hand, the laptop loaded with software-it's theirs - in the other, and their own business waiting for them when they walk off the stage" (MW-NE-1). This same story was related by the vice president of academic affairs: "We occasionally used the notion that a student who would graduate had a diploma in their hand and that business plan under their arm, but at the same time would have a laptop under their arm as well. So you would have this three overlapping globes of academic programs, entrepreneurial initiatives, and applied business practices, all of which is encompassed in this sort of infusion or environment of technology." And the dean of enrollment management echoed, "The president has students in mind. He envisions a student at graduation that has a diploma in one hand, a business plan in the other hand, and a laptop under their arm." Clearly, the president's vision for a campus that integrated technology with entrepreneurialism and student learning is reinforced by messengers in the leadership cabinet who shared this vision with other campus members. 
Star or open networks are the final communication pattern in Lunenburg and Ornstein's (2007) typology. In colleges that communicate via star networks, an individual has open communication lines not only to others at the same level (those located to each side of them in the network), but also with those who work in different parts of the college or who operate at different levels (those who may be located on the other side of the star). Communication with these latter individuals is represented by the intersecting lines of the star. In star networks, emissaries are located at all points of the organization and can communicate freely across the institution. Ties to the community are also included in this type of communication network. One faculty member at a college in the northeast noted a conversation she overheard at the local discount store. She said, "I was just doing Christmas shopping and I heard some older people there in the aisle and I heard them talking about the college.... And it was interesting because they were, [changes voice to sound raspy] "Oh things have really changed over there" and they said, “They're getting four-year degree programs now and they're not a two-year college anymore and things are so different!" The changes in the college had become obvious to the community because college constituents had served as conduits for that information. In this case, because the president's (FW-NE-2) vision for the future of the college was clearly transmitted within the organization, it was also cohesive when it was conveyed outside the campus.

The president of a community college in the southwest intentionally used his campus colleagues to convey messages to the greater community. As he said, "You have to communicate. People have to feel positive. The internal community has to feel positive....The communication radiates out. So, if I've got 400 employees and they talk to 10 people a month about the college, then that's 4,000 contacts. Multiply that by people who talk to key influencers, it's probably 
8,000-10,000 people" (MW-SW-4). When campus communication is open and the leader has clearly framed a message, everyone on campus can serve as a messenger.

Star networks provide leaders with the greatest amount of feedback because instead of receiving information from a small number of individuals, they can gather varied viewpoints from multiple campus members. As the president in the southwest noted, "There's a filter there when you are around the president. You have to get out of that layer of insulation" (MW-SW-4). Getting out of isolated streams of communication provides opportunities for presidents to engage in feedback loops with campus constituents, which can challenge assumptions and allow for change. It is important for leaders to move beyond a circle of "yes" associates to allow for critical reflection on their leadership and their decisions. As an example, the president of one of the campuses in the south actively solicits feedback from faculty and staff. As he related, "I encourage people to contact me-e-mail, mail, voice mail, or any way that they need to reach $m e$ " (MB-S-7). Allowing for a variety of ways to provide feedback to campus leaders can result in a greater amount of feedback, as individuals who might not participate in formal feedback sessions can communicate with leaders in their preferred format.

\section{Getting the Message Across}

As noted, college presidents must first make sense of new information themselves, then they must frame their message, and finally they must use messengers to help disseminate that information to the rest of the community. In the dissemination stage, college leaders and their messengers can use four distinct methods for getting a message across. These methods include Talking the Frame, Walking the Frame, Writing the Frame, and Symbolizing the Frame. It is important to note that different leaders may be more comfortable with some of these communication methods over others, depending on their leadership preferences. Key to 
effectively framing and communicating information is the alignment of message to messenger; there is no right way to communicate or lead. Leaders must understand their communication strengths and rely on messengers or emissaries to communicate a message in ways that they cannot.

Trying to assume a communication style that conflicts with an individual's leadership style could be less than effective (consider how a structured leader may flounder in a campus town hall meeting in which questioning is random, or how a shoot-from-the-hip communicator would feel if required to stick to a scripted speech). Leaders must understand their communication strengths and rely on messengers or emissaries to communicate a message in ways that they cannot. For example, a president may be comfortable walking the frame and talking the frame, but may not be an effective writer; in this instance, she may rely on a vice president for written communications with the campus community. The following sections highlight the variety of ways in which the presidents in this study used the four communication methods to get their message across to campus constituents and to help them make sense of that information.

\section{Talking the Frame.}

Campus members often learn about new change initiatives during open campus forums or in small group discussions. These meetings may occur at the beginning of the year or during regularly scheduled times, providing excellent opportunities for college leaders or their messengers to Talk the Frame (i.e., verbally discuss the information in a way that is consistent with the leader's frame). Talking the Frame can also occur in ad hoc meetings pertaining to specific campus needs, events, or challenges. 
In Talking the Frame, campus leaders can speak in a more formal, scripted format, or in a more freestyle manner, depending on the leader's preferences and the particular way in which she has chosen to frame the message. For example, the woman president in the northeast described Talking the Frame during a typical large group session on her campus. Her approach during the fall of her first year on campus had been to listen to campus members and to scan the college environment in order to uncover current issues, possibilities, and threats. She noted, "In January at the opening of the spring semester, I presented my Program of Work, it has eight goals. I did it in a generic way and I said these are the area that I'm going to be paying attention to over the next 18 months" (FW-NE-2). This session was formal in orientation with a PowerPoint program outlining each of the eight steps. The president supplemented her verbal presentation with written information. Nonetheless, campus members could not readily recall the name of the strategic initiative, sometimes referring to it as "The President's Plan" or saying, "What'd she call it? Thing of Work?" The plan itself did not conjure up a feeling of solidarity or ownership among campus members. Although the president Talked the Frame, the formalized way in which she did so may have prevented campus members from seeing their own contributions to the plan, and did not allow enough dialogue to create shared meaning.

The president in the southwest (MW-SW-4) Talked the Frame in a different way, relying on small group meetings to frame messages. A faculty member at the college shared, "We have the Vision Shared Meeting every Monday, and then every other week we have Learning Services Council and that includes all of instruction, chairs, deans, vice presidents, directors of our offcampus sites, and support office representatives." Another faculty member underscored the importance of talking about the campus vision by stating, "Often what seems to be the safest way is a meeting with all people because you can be assured they get the same type of message." 
Thus, by talking about the president's message at many different meetings, the college community was able to arrive at a shared understanding of the actions that needed to be taken.

\section{Walking the Frame.}

Another method of conveying a particular message is to Walk the Frame. Campus leaders and their emissaries can do this by acting in ways that are consistent with the leader's message, and through leading by example. Walking the frame occurs in informal, casual conversations with college presidents and others carrying the message, both on campus and off campus, with the ultimate outcome of getting the framing message out in the trenches. For one of the male presidents in the southern district, open communication among all levels of campus constituents was an important goal, and one he worked hard to convey to the faculty and staff. He felt that creating personal connections with campus members was a critical part of his job; being approachable was a critical leadership attribute. In order to Walk this Frame, the president said, "I set up private meetings with everybody who works here. So all the employees get to visit with me-I don't really have an agenda. They can talk about their work, they can talk about their families, whatever they want to do. Each meeting is about 15, 20, 30 minutes. It's very important for me to get to know everybody" (MW-S-5). These meetings helped the president to effectively Walk the Frame he wanted to convey: that open communication is important and necessary on campus.

Being available and present to campus members sends a strong message from the president. Presidents who are perceived as less accessible may not be considered by campus members as understanding the real needs of campus stakeholders and hence have less of a connection when trying to frame events. A male president in the southern district believed in the 
importance of establishing relationships. According to a faculty member, "If I had to describe [the president], I would say he uses his personality, his personal relationships with people. He believes in getting out and being visible. He's an extremely dynamic speaker and that energy comes through when he's addressing the faculty" (MB-S-7). Similar observations about the male president of the college located in the northeast (MW-NE-1) were made by faculty members and administrators at that institution. Staff members commented that it was common to see him out and about on the campus and at events. These chance encounters served to underscore the connection the president has with the campus. The informal nature of these interactions provides leaders with yet another opportunity to build relationships and influence campus opinions. The random encounters the president has on campus are more or less accepted by staff members depending on established relationships and past experiences. For instance, faculty members may think a president is coming to "check up on them" if walking about campus and interacting with staff are infrequent or happen to correspond with other events, such as accreditation visits, negotiations, or rumors of staff reductions.

\section{Writing the Frame.}

Yet another method for communicating a message to campus constituents involves Writing the Frame. Presidents and their messengers can use written policies, reports, strategic plans, memos, meeting notes, web postings, or e-mails to inform college members of current events and provide new information about campus decisions and requirements. Formal ways of Writing the Frame include written policies, reports, and strategic plans. Leaders who are more comfortable in structured or hierarchical environments may prefer to Write the Frame using these more formal forms of communication. 
Other leaders may prefer to communicate with the campus community through more informal venues, including e-mails, blogs, wikis, and websites. One president shared, "I try to send periodic e-mails, I call them Presidential Ramblings, I just ramble about the things that are going on" (MW-NE-1). This informal format aligned well with his more fluid communication preferences. Another president (FW-NE-2) also sent out campus e-mails, but hers tended to be more formal and underscore points she want to reiterate about the campus strategic plan. The president from the southwest (MW-SW-4) may be an unusual leader in that he effectively Writes the Frame in both formal and informal ways. He makes heavy use of the college's strategic planning document with referrals to this plan in regularly schedule meetings, and he also makes use of writing news articles for the local paper and scripts for the college television station.

Because getting large groups together can be difficult on community college campuses, memos can be an effective means of getting messages out to faculty and staff. Indeed, some people prefer to receive information in a written format so that they can review new initiatives at their own speed and to have the time to repeatedly read the material. Sending out detailed plans in this manner and keeping policies and plans posted on the college website can help communicate a leader's message to campus members. However, making information available does not ensure that staff actually read the material (recall the staff at the northeastern college noted above who could not remember the name of their president's strategic initiative).

Enlisting other campus constituents to help Write the Frame can help to cement a president's vision for the future and drive home a particular message. One faculty member at a newly-established college in the southern district discussed how written communication had benefitted the campus, and in particular its understanding of learning communities. She stated, “There is more in writing about the problematic initiatives and start-ups so that's there's not this 
wishy-washy perception of what a learning community is. We're doing white papers-they're faculty driven for the most part-well, some are faculty driven, some are administrative driven only because they were here beforehand and they spent a lot of time up front I think really thinking about why they want the district to be" (FW-S-6). At this new college, both faculty and administrators were engaged in writing about the new campus' goals and challenges, which ultimately helped them come together with a unified vision of the institution and its mission. Writing the Frame may be an especially effective method of communicating on campus when a leader is less skilled in Talking the Frame. As an example, the director of public relations at the western college offered an assessment of her president, saying, "She's very shy, and so many times I've tried to encourage her to take doughnuts to staff meetings and just try to get to know people. I think that it has been somewhat unfortunate because people haven't gotten to see what a wonderful person she is, because she hasn't had the personality to go and sit in on staff meetings, and by the other side of it hasn't been able to have regular conversations with a lot of people, or hasn't chosen to have" (FW-W-3). This western president knows where her strengths lie. As she stated, "Well, I write obviously and that seems to work for this group. There is an essay on the website on the President's Page on workforce education, so that's a mechanism I use" (FW-W-3). Although the president relies on her communication strengths, focusing on Writing the Frame, she might benefit from using messengers to Talk and Walk the Frame for her, as relying on one form of getting messages out at the expense of others can result in an inability to reach some campus members who prefer to learn about issues in particular ways.

\section{Symbolizing the Frame.}


Finally, leaders can communicate information to their constituents by Symbolizing the Frame. By using particular symbols, either literal or metaphorical, presidents can provide faculty and staff with a particular lens for understanding the president's vision, interpretation of campus mission, or ideas for organizational change. Some presidents used symbolism intentionally and were comfortable doing so, but others missed opportunities to get their messages across because they did not engage in Symbolizing the Frame.

The president of the campus in the southwest was adept at using symbolism, and sought out occasions such as his weekly television show on the college station to highlight campus events (MW-SW-4). Similarly, the male president in the northeast called attention to issues he wanted to highlight (in particular the restoration or renovation of campus facilities) by hosting meetings and forums in new campus buildings. As one campus member noted, "The reason [that morale is so high is that we have so much going on in terms of new buildings. We opened four new buildings and that in itself gets you all charged up" (MW-NE-1). By holding meetings in strategic locations, the president was able to leverage the completion of new facilities in order to symbolize forward movement of the college.

Campus stories are a central component of Symbolizing the Frame. Stories told by the president or other campus members to one another serve as a means of passing along information on campus. As well, when new presidents can clearly communicate an understanding of longstanding college stories or sagas, they are more likely to be judged positively by campus constituents. This was particularly true when a new president in the study was able to communicate to the faculty and staff that, unlike the previous leader, she would not operate in an autocratic way. For instance, at one of the northeast site colleges, one of the previous presidents would sit in his office with the blinds drawn, personifying a recluse who was not connected to 
the campus. Because the new president understood how the former president's actions had affected faculty and staff members, she was able to act in a different way, effectively conveying the message that a new era of leadership had arrived (FW-NE-2).

Clark (1972) wrote about the importance of the institutional saga on college campuses. The stories recounted by leaders help to define campus culture and in turn help presidents frame their messages. At the new college in the southern district, the president continually underscored the ideal of equity among students and staff in the learning process. In order to Symbolize the Frame, she, "decided that there would be no reserved parking because we believe that students are as important as faculty and administrators" (FW-S-6). Although this act symbolized to students that they are at the center of the college, some faculty members felt that their status had been devalued. This example illustrates the necessity of using more than one method of getting a message across. Symbolizing the Frame worked for the students, but the president and her administrators also needed to communicate with the faculty about how they arrived at this decision so that they (the faculty) did not feel less valued. Perhaps if the decision had been more clearly framed for the faculty and staff, explicitly showing how unreserved parking benefits a culture of student-centered learning, the president and her administrators would not have received the push-back that they experienced. Clearly, Talking the Frame, Walking the Frame, Writing the Frame, and Symbolizing the Frame are all important ways to get a message across to campus constituents. One method might be more appropriate than another at any given time, and sometimes more than one method (or even all four) should be employed by a leader and her messengers to ensure that faculty and staff members are able to understand new information from the perspective that the leader feels would most benefit the campus. 


\section{Discussion}

Leaders use a variety of methods to frame campus member attention. The president of a college in the south related how her campus created its institutional story. She said, "We have a formal orientation process that's really fun. It involves the ducks-our mascot is the ducks because they paddle like crazy under the water but they're calm on the outside and that's our customer-service philosophy. Everybody, full- or part-time, police officer to custodian, goes to the customer-service training. That's the first thing they do-that helps builds our culture a little bit" (FW-S-6). Although in this instance a metaphor helped the president frame information about the new customer-service training to her faculty and staff, leaders must be careful not to incorporate complex metaphors or institutional sagas that do not have shared meaning for constituents. The leader needs to carefully ensure that the intended message and the meaning actually understood are the same.

Symbols and stories can also help to frame and communicate a message (Bolman \& Deal, 2008; Frost \& Morgan, 1983). Indeed, leaders can use symbols to draw attention to specific versions of a campus story they are creating. The president of the college in the southwest used several logos and symbols to sell his new mission statement. These images were added to all of the signs on campus and were incorporated into college business cards. He also had the five-year strategic plan bound with a red cover to signify its importance. Campus leaders frequently relied on their little red books in campus meetings and monthly progress updates-it was a living document and was integral to how the president framed change and priorities on campus (MWSW-4). Similarly, the president of a college in the northeast created a logo for the college that emphasized the campus' entrepreneurial students and dedication to technology and student 
learning. The fact that multiple campus members recited the meaning of the logo almost verbatim underscores how effective it was as a symbol for the president's (and thus the college's) vision for the future (MW-NE-1).

It is clear from the above examples that the ways in which a leader frames information greatly affects how faculty and staff members respond, and in turn has an impact on campus operations. Community college presidents have several opportunities to directly communicate information to campus constituents, but because they are not omnipresent, they must often rely on a messenger to communicate their views and ideas. Communicating with the campus community—in particular, conveying certain messages and visions for the future—is essential for a community college leader and is an important element of multidimensional leadership. Three distinct forms of communication were observed in the analysis of the findings: visionary framing, step-by-step framing, and connective framing. Through experience and feedback, a leader may shift from an autocratic, hierarchical mode of communication to an inclusive and multifaceted mode that captures campus feedback and makes adjustments. As with other aspects of leadership, as individuals learn more about themselves and, through experience, about what works on campus, they can begin to shift their mental maps of how they communicate.

\section{Visionary Framing}

Some leaders choose to focus campus members' attention on the college's future and possibilities rather than on the current state of the campus. Visionary framing relates to the final property of Weick's (1995) sensemaking model—namely, framing information in terms of plausible (as opposed to accurate or current) outcomes. Framing information in a visionary way requires college leaders to operate on the cusp of uncertainty (Morgan, 2006), but may be 
especially useful in turbulent and uncertain times, as it allows followers to focus on the college's possibilities rather than on its realities. Framing a vision requires extensive verbal, non-verbal, and written communication, but communicating through symbolism can be especially effective. The president in the southwest was successful in framing and communicating his vision for the college largely because he was an adept symbolic framer. This helped faculty and staff members relate to him and his goals, which translated into greater support for his vision. As one faculty member stated, "My second semester I started listening to what the president was saying, to his vision and I thought, wow, I can really identify with this person. We have the same values about education and where he sees the college wanting to go. I got excited-this is someone who is not just taking a job, he's got a vision and direction as to where he wants to go with the college!" The president was especially successful in framing his vision for the college because he asked for input and listened closely to others' advice. Another faculty member touched on this point, adding, "[The president (MW-SW-4)] talks to different people according to where their expertise is and then makes the best decision he feels is appropriate to direct us in the right way." Even though the president had developed his own vision for the college, he ensured buy-in from campus members, his leadership team, and external stakeholders by allowing them to have a voice in the process.

Likewise, the president of one of the campuses in the northeast was also able to successfully frame his ideas for change at his college, in particular his ideas for a technologically-integrated, student-centered campus. As one long-serving faculty member stated, "He's probably the closest to a visionary I've seen in many years, the first one that I've seen on this campus in 22 years. He's visionary. He has ideas. Some of his ideas include putting a telephone in every student's hand and those kind of things were well received" (MW-NE-1). 
As the president's vision for this northeastern college started to become a reality, he found it even easier to frame and communicate his ideas and receive acceptance from campus constituents. As he shared,

You know we were ranked nationally as the most wired campus. The first time that happened I think people were in a state of shock. Now we just got it again and that's something they never envisioned. It's a national ranking by an outside organization and it's phenomenal. Being written up in the Chronicle of Higher Education, being recognized as being very technical. The campus believes that now. They believe we are the most technical campus around. The third and fourth phase of our plan goes into effect next year and they just sort of look at me and shake their head. This concept of understanding the application of technology and it being integrated throughout the classroom activities and student life on this campus is pervasive. They understand that. That's been accomplished (MW-NE-1).

Although campus constituents at the college were initially skeptical about the integration of technology, the outside recognition and the continued messages from the president about how technology was the future helped the faculty claim his vision as their own. His visionary framing focused their attention on the future, and at the same time he worked behind the scenes to put together the structures necessary to support the vision.

\section{Step-by-Step Framing}

Not all leaders are adept at framing information in a way that is visionary. Indeed, although most community college presidents have ideas about what they would like their college to look like in the future, many find it easier to focus their own attention (and that of campus 
constituents) on the immediate next steps in accomplishing the longer-range goals. Although this framing method can be effective in moving the college along, leaders sometimes forget to remind campus members of the final destination - the reasons why they are doing what they are doing. Nonetheless, framing information in a step-by-step manner can still lead to successful campus ventures.

The president of the second site college located in the northeast provides an excellent example of a leader who frames and communicates information in a step-by-step manner. She inherited a campus with serious issues, including low enrollment, revenue losses in auxiliary services, debt from a failed venture, and overspending of scholarships relative to foundation income. By communicating the immediate next steps in fixing these problems, the president (FW-NE-2) succeeded in remedying three of the four issues she faced within two years. However, although her leadership staff knew of this progress, the overall campus did not. Moreover, even as she spoke frequently about her eight-step Program of Work, some campus members did not make the connections between their contributions during break-out sessions and small group meetings with the president and campus progress toward the goals outlined in the Program of Work. Ultimately, although the president was able to move her campus forward, campus constituents lost focus on her overall vision for the future. Focusing on immediate needs and celebrating short-term successes can be enormously helpful in systematically moving a college campus toward a president's vision. However, campus leaders must continually work to help faculty and staff members make sense of that forward progress, and remind them how each step contributes to the overall vision.

\section{Connective Framing}


Leaders who frame information in a connective manner create a reality in which the campus learns and grows together (Fairhurst, 2001). These leaders work closely with campus members to create and communicate a vision for the institution. Connective framers often rely on connected ways of knowing (Belenky, Clinchy, Goldberger, \& Tarule, 1997) and emphasize understanding, empathy, acceptance, and collaboration. Often connective framers are transformational leaders who prioritize dialogue. Connective framers work collaboratively with constituents across campus and frame issues from multiple perspectives so that campus members can see the not only the next steps, but also the future direction of the college. Sensemaking is therefore central to connective framing.

According to Birnbaum (1988), framing information in a connective way "means providing forums for interaction in which the 'negotiations' that determine reality can be carried out, making more explicit the assumptions behind present rules and ongoing processes so that they can be accepted or challenged, and giving prominence to certain activities that can serve as attention cues for others in the institution" (p. 78). Connective framing provides opportunities for dialogue and allows leaders and followers to collectively determine what assumptions they bring to the table and discuss how these assumptions help or hinder the forward movement of the college.

One of the presidents in the southern district (FW-S-6) is an example of a connective framer. Because the campus was new, there were many opportunities to build the college into an institution that valued and prioritized student learning. As the president reflected, "The vision came out of the ability to build a college from scratch in the $21^{\text {st }}$ century, taking best practice of everything we all wish we could do but can't because there's always limitations either by organizations or by people you have employed, or by habit, or by physical plant" (FW-S-6). The 
organizing team spent a great deal of time talking about how they wanted to make the college operate in a different way from "traditional" colleges. The leadership team sought to intentionally capture the recommendations of all the initial task force teams so that a diversity of voices were heard as the college was being created.

In order to assure that the new college maintained some consistency with the larger institutional history and saga of the southern district, the district chancellor required the president to hire $50 \%$ of her staff from within the district. Thus, the president felt that it was her job "to keep the collaborative process on track and make sure we get the outcome, we communicate the outcomes, and that we involve the people" (FW-S-6). Consensus building was at the center of the president's connective framing process.

Another element at the core of connective framing is making information abundant across all levels of the campus. Transparency in communication and in decision-making allows individual campus members to feel a part of the process. A president at one of the southern district campuses described the changes he had implemented at his college and the connective ways in which he worked to build a jointly-created culture. He stated,

These people don't really know how to make group decisions. They know how to make decisions in their own particular area and they know how to carry out decisions that have been given to them, but they have never been part of a decision-making process in any real way and they're not used to making decisions as a group. We had to take a 3 percent cut to this year's budget. They brought those decisions to the table. Before it was a game of conceal and hope they don't find you and when they do, you give it up. Now, they had to do the opposite. They had to go round and round the table until we reached that amount of money. People were starting to collaborate with each other, they would 
say, "Well, I can give up something here" and "You shouldn't have to do that, that's too important." Everybody felt really good about that meeting. (MW-S-5)

By framing the budget cuts in a connective manner, the president helped the campus come to a consensus on how and where to make the cuts. Leaders operating from a connective perspective use the star model of communicating, adjusting actions based on these interactions. This reflects the fact that connective leaders don't rely simply on their own thoughts and orientations, but rather take into consideration a wide array of perspectives. Thus their leadership occurs in many ways through the facilitation of dialogue on campus. As such, connective leaders must be skilled in communicating in multiple formats (i.e., walking the frame, talking the frame, etc.).

\section{Conclusion}

Communicating with the campus community—in particular, conveying certain messages and visions for the future - is essential for community college leaders. As with other aspects of leadership, as individuals learn more about themselves and, through experience, about what works on campus, they can begin to shift their mental maps of how they communicate. The evidence from the data helped to create three distinct forms of framing that the participating presidents used. These include: Visionary Framing, Step-by-Step Framing, and Connective Framing.

Some leaders choose to focus campus members' attention on the college's future and possibilities rather than the current state of the campus. Visionary framing focuses on creating a sense of possibilities versus concentrating on current realities. Framing information in a visionary way takes advantage of contextual uncertainties and provides a particular vision of the future for campus members crafted by the campus leader. Framing a vision requires extensive 
verbal, non-verbal, and written communication, but communicating through symbolism can be especially effective. Two of the participating presidents relied on this type of framing.

Not all leaders are adept at framing information in a way that is visionary. Indeed, although most community college presidents know where they would like to make changes on campus and have their own vision of the future, they get caught up in present and immediate concerns that require short-term actions. These current responses contribute to the over-all vision for the college, but do not always acknowledge the future destination. Campus leaders coming from this frame continually work to help faculty and staff make sense of that forward progress, and remind them how each step contributes to the overall vision. The majority of participating presidents used this form of framing, relying on more bureaucratic organizational operations and less on open forms of communication.

Leaders who frame information in a connective manner create a reality in which the campus learns and grows together (Fairhurst, 2001). These leaders work closely with campus members to create and communicate a vision for the institution. Connective framers emphasize and engender understanding, empathy, acceptance, and collaboration among followers (Belenky et al., 1997). Sensemaking is central to connective framing. Two of the participating presidents utilized connective framing. The forums created for dialogue provide an opportunity for the group to determine their shared values and acknowledge the assumptions individuals are making about the situation at hand. Connective framing provides opportunities for this level of dialogue to occur.

Several implications may be drawn from this research. First, leaders must reflect on their preferred modes of communicating and realize that campus members similarly have preferences in how they receive messages. How leaders communicate is based on their own preferences, but 
adeptness at multiple forms of getting the message out to campus members assures that more stakeholders are hearing the message and making sense out of campus priorities. Here, the use of emissaries provides additional means of framing, in particular in venues that are not preferred by the president. Second, hiring boards of trustees should consider the institutional saga of the college, the issues facing the campus, and the vision for the future as they select presidents. The communication style of the president sets the tone for how campus members perceive proposed change and how stakeholders interpret campus plans. Visionary framing may provide the best fit for a campus seeking to shift its focus or to venture in new areas, whereas step-by-step framing may better serve a campus with obtaining strategic objectives already underway. Connective framing may be most appropriate for a campus in need of building community both within and outside of the college. Key to hiring decisions then is finding a fit between campus needs and a president's approach to framing. Finally, leadership development programs at universities or in professional associations should include skill building around the importance of framing. The complexity of today's community colleges can leave faculty and staff members adrift because they receive multiple, and oftentimes conflicting, messages regarding campus initiatives. It is critical to train the leaders of the future first, to understand the importance of framing messages to the campus and second, to become skilled in the various forms of framing (i.e., taking, walking, writing, and symbolizing). Leaders have great power in managing the messages of change on campus that can help move their organizations forward. Skills in framing provide a valuable asset to community college leaders as they provide meaning for campus members and initiate organizational changes to meet the demands placed on two-year campuses. 


\section{References}

Belenky, M. F., Clinchy, B. M., Goldberger, N. R., \& Tarule, J. M. (1997). Women's ways of knowing: The development of self, voice, and mind. New York: Basic Books.

Berger, P. L., \& Luckmann, T. (1966). The social constructivism of reality: A treatise in the sociology of knowledge. Garden City, NY: Doubleday \& Company, Inc.

Birnbaum, R. (1988). How colleges work: The cybernetics of academic organization and leadership. San Francisco: Jossey-Bass Publishers.

Bolman, L. G., \& Deal, T. E. (2008). Reframing organizations: Artistry, choice and leadership. San Francisco: Jossey-Bass.

Clark, B. R. (1972). The organizational saga in higher education. Administrative Science Quarterly, 17(2), 178-184.

Eddy, P. L. (2003). Sensemaking on campus: How community college presidents frame change. Community College Journal of Research and Practice, 27(6), 453-471.

Fairhurst, G. T. (2001). Dualisms in leadership research. In F. Jablin \& L. Putnam (Eds.), The new handbook of organizational communication: Advances in theory, research, and methods (pp. 379-439). Thousand Oaks, CA: Sage Publications, Inc.

Fairhurst, G. T., \& Sarr, R. A. (1996). The art of framing: Managing the language of leadership. San Francisco: Jossey-Bass.

Frost, P. J., \& Morgan, G. (1983). Symbols and sensemaking: The realization of a framework. In L. R. Pondy, P. J. Frost, G. Morgan, \& T. C. Dandridge (Eds.), Organizational symbolism (pp. pp. 207-236). Greenwich, CT: JAI Press Inc.

Kelman, H. (1961). Process of opinion change. Public Opinion Quarterly, 25(1), pp. 57-78.

Lunenburg, F. C., \& Ornstein, A. C. (2007). Educational administration: Concepts and practices (5th ed.). Belmont, CA: Wadsworth.

Merriam, S. B. (1998). Qualitative research and case study applications in education. San Francisco: Jossey-Bass.

Morgan, G. (2006). Images of organization. Thousand Oaks, CA: Sage Publications, Inc.

National Center for Education Statistics. (2007). Digest of Education Statistics: 2007. Washington, DC: US Department of Education. (NCES No.2008-022). Retrieved August 30, 2008, from http://nces.ed.gov/programs/digest/d07/

Neumann, A. (1995). On the making of hard times and good times. Journal of Higher Education, 66(1), 3-31. 
Peterson, M. (1997). Using contextual planning to transform institutions. In M. Peterson, D. Dill, L. A. Mets, \& Associates (Eds.), Planning and management for a changing environment, 127-157. San Francisco: Jossey-Bass Publishers.

Senge, P. M. (1990). The Fifth Discipline: The Art and Practice of the Learning Organization. New York. Doubleday.

Smircich, L., \& Morgan, G. (1982). Leadership: The management of meaning. The Journal of Applied Behavioral Science, 18(3), 257-273.

Stake, R. (1995). The art of case study research. Thousand Oaks, CA: Sage.

Thayer, L. (1988). Leadership/communication: A critical review and a modest proposal. In G. M. Goldhaber \& G. A. Barnett (Eds.), Handbook of organizational communication (pp. pp. 231-263). Norwood, NJ: Ablex.

Van Manen, M. (1990). Researching lived experience: Human science for an action sensitive pedagogy. Albany: State University of New York Press.

Weick, K. E. (1995). Sensemaking in organizations. Thousand Oaks, CA: Sage Publications.

Weisman, I. M., \& Vaughan, G. B. (2007). The community college presidency 2006. Washington, DC: Community College Press. 